\title{
The Research of City Emergency Rescue Based on the Intelligent Systems
}

\author{
Ning Han \\ School of North China Electric Power University, Baoding 071000, China \\ hannahning@163.com
}

\begin{abstract}
This paper mainly focuses on the emergency rescue of a city, and set up a reasonable plan for the ambulance. Two evaluation principles are defined: firstly, an ambulance can arrive at the designated area within 8 minutes of the specified time; secondly, the people who get help as much as possible. According to the above two principles, we set up the ALU logic circuit model. In view of the different situation, it has worked out the plan of the ambulance when there is no emergency.
\end{abstract}

Keywords: City emergency rescue; ambulance; Floyd algorithm; ALU (arithmetic logic unit) logic circuit model; 0-1 programming model; the matlab and Multisim simulation.

\section{Introduction}

Initially, the ALU logic circuit model is established, and the shortest time is calculated by using the Floyd algorithm. Secondly in the ALU model, the three state gate control is used to determine the characteristics of the circuit, which can be used for emergency treatment. Then use the software Matlab to solve the program, meanwhile, calculate the coverage rate of the above scheme. Finally, getting the final results of the ambulance in NO.2, NO.2, NO.6 or NO.2, NO.2, NO.5 area are the best.

\section{Model assumption}

The rescue capacity of each ambulance is basically the same.

Each area is only for an ambulance.

Each ambulance at least rescue one area.

The ambulance reaches the designated area in the shortest time.

\section{Symbol description}

$t_{\mathrm{ij}}$ : i stands for the ambulance on the $\mathrm{i}$ area, $\mathrm{j}$ stands for the ambulance arrived at the $\mathrm{j}$ area, $t_{\mathrm{ij}}$ stands for the shortest time from i to $j .(i=1,2 \ldots 6 ; j=1,2 \ldots 6)$

$\mathrm{k}_{i j}$ : when $\mathrm{k}_{i j}=1$, the ambulance $\mathrm{i}$ can arrive at $\mathrm{j}$ in $8 \mathrm{~min}$; when $\mathrm{k}_{i j}=0$, the ambulance $\mathrm{i}$ cannot arrive at $\mathrm{j}$ in $8 \mathrm{~min}$.

$\mathrm{x}_{i}$ : the ambulance is on the $\mathrm{i}$ area.

$\mathrm{S}$ : coverage of the ambulance

$y_{i j}$ : the ambulance which is on the area of i rescue area $j$.

$\mathrm{a}_{i}$ : i district people/the total number of people

\section{Model analysis}

On the left of the six switch represents the location of the ambulance in the six area, when the switch is 1 (closed), standing for the ambulance in the area; switch is 0 (disconnect), not in the region.

Whether the actual problem of the ambulance cover six areas into the current which can through three series of six state gate, output to the right end of the light-emitting diode. Because only when the six state gate are open (the six regions can be reached), the normal light-emitting diode. 
When $t_{\mathrm{ij}}<8 \mathrm{~min}$, the region $\mathrm{j}$ by ambulance i rescuing, but it is also possible by other ambulances rushed to the rescue in the $8 \mathrm{~min}$, and $\mathrm{k}_{i j}$ may be closed or be disconnected; when $t_{\mathrm{ij}}>8 \mathrm{~min}$, the region $\mathrm{j}$ cannot be rescued by the ambulance $\mathrm{i}$, and $\mathrm{k}_{i j}$ certainly be cut off. At the same time, the degree of coverage of each result is obtained by comparing the size of the degree. Finally get the optimal solution.

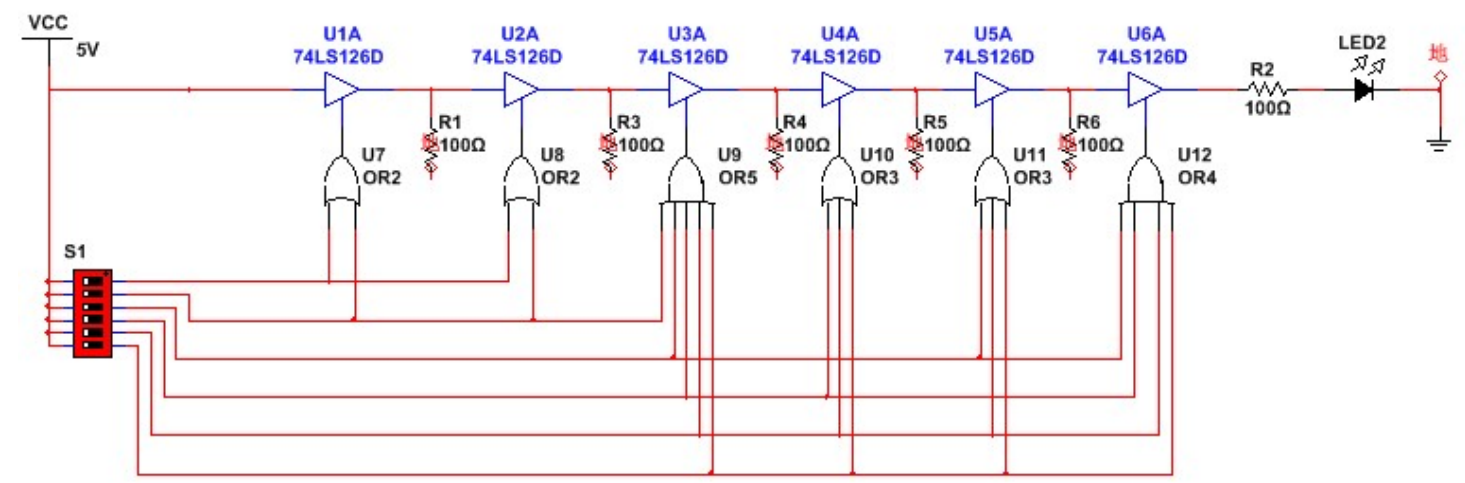

Fig. 1 The model of ALU logic circuit

\section{The establishment and solution of the model}

Step1. Solution of the shortest time

Using the Floyd algorithm to calculate the shortest time between each area arrive at the specific region as Table 2.

Table 2: Arrive at the area required minimum time (min)

\begin{tabular}{c|c|c|c|c|c|c}
\hline Area & 1 & 2 & 3 & 4 & 5 & 6 \\
\hline 1 & 1 & 8 & 12 & 14 & 10 & 12 \\
\hline 2 & 8 & 1 & 6 & 16 & 12 & 10 \\
\hline 3 & 12 & 18 & 1.5 & 10 & 6 & 4 \\
\hline 4 & 16 & 14 & 4 & 1 & 10 & 8 \\
\hline 5 & 18 & 16 & 6 & 4 & 2 & 2 \\
\hline 6 & 16 & 18 & 4 & 6 & 2 & 2 \\
\hline
\end{tabular}

Further finishing of the form, the area where the ambulance can be treated in a certain area, such as Table 3.

Table 3: Treatment range (area)

\begin{tabular}{|c|c|}
\hline Ambulance position & Can get emergency rescue position \\
\hline 1 & 1,2 \\
\hline 2 & $1,2,3$ \\
\hline 3 & $3,5,6$ \\
\hline 4 & $3,4,6$ \\
\hline 5 & $3,4,5,6$ \\
\hline 6 & $3,4,5,6$ \\
\hline
\end{tabular}

Step2. Specific model

$\mathrm{x}_{i}=1(i \in[1,6])$ standing for the ambulance is on the area $\mathrm{i}$, now $y_{i j}=1$. Because of the need to place three cars, we have to make the amount of $x_{i}=1$, which is equal to 3.And make y1-y6=1 as much as possible. Expressions are as follows:

Objective function: $f=\max \sum_{i=1}^{6} \sum_{j=1}^{6} y_{i j}$ 
Constraint condition: $\sum_{i=1}^{6} x_{i}=3$

Step3. Calculation of the degree of coverage

Degree of coverage: $S=\sum_{i=1}^{6} x_{i} \times a_{i}$

\section{Conclusion}

The final results show that all the regions of the personnel are entitled to a total of 22 kinds of rescue protection schemes such as Table 4.

Table 4: Various allocation schemes

\begin{tabular}{|ccccc|}
\hline $\begin{array}{c}\text { Arrangement } \\
\text { methods }\end{array}$ & Area & 6 & $\begin{array}{c}\text { Degree of } \\
\text { coverage }\end{array}$ \\
\hline One & 2 & 5 & 6 & 1.6296 \\
\hline Two & 2 & 4 & 5 & 1.5 \\
\hline Three & 2 & 4 & 6 & 1.5 \\
\hline Four & 2 & 3 & 5 & 1.4259 \\
\hline Five & 2 & 3 & 4 & 1.4259 \\
\hline Six & 2 & 3 & 6 & 1.2963 \\
\hline Seven & 1 & 5 & 6 & 1.5185 \\
\hline Eight & 1 & 4 & 5 & 1.3889 \\
\hline Nine & 1 & 4 & 6 & 1.3889 \\
\hline Ten & 1 & 3 & 5 & 1.3148 \\
\hline Eleven & 1 & 3 & 4 & 1.3148 \\
\hline Twelve & 1 & 3 & 6 & 1.1852 \\
\hline Thirteen & 1 & 2 & 5 & 1.5926 \\
\hline Fourteen & 1 & 2 & 5 & 1.5926 \\
\hline Fifteen & 2 & 2 & 6 & 1.7037 \\
\hline Sixteen & 2 & 2 & 5 & 1.7037 \\
Seventeen & 2 & 5 & 6 & 1.6296 \\
\hline Eighteen & 2 & 6 & 6 & 1.6296 \\
\hline Nineteen & 1 & 1 & 5 & 1.4815 \\
\hline Twenty & 1 & 1 & 6 & 1.4815 \\
\hline Twenty-one & 1 & 5 & 1.5185 \\
\hline Twenty-two & 1 & 5185 \\
\hline Comparing & $30 v e r g e$ & 5 & 1.515 \\
\hline
\end{tabular}

Comparing the coverage of the optimal plan for the NO.2, 2, 6 or NO.2, 2, 5 area, the citizen can enjoy 8 minutes of emergency rescue services, and the degree of coverage is 1.7037.

\section{References}

[1] Wang Moran. MATLAB and Science. Beijing Electronic Industry Press, 2008.

[2] Chen Yanyan. The optimized layout of urban fire station [J].Fire science and technology, 1999.

[3] Fang Shichang. Discrete mathematics. Xian Electronic and Science University Press, 2009.

[4] Wu Meiwen. Optimal layout method of urban fire station based on discrete location model, 2006. 